\title{
Relato de experiência: curso de introdução à programação para crianças do ensino fundamental no IFSP Votuporanga
}

\author{
Luciene Cavalcanti Rodrigues ${ }^{1,2}$, Ana Paula Garrido de Queiroga ${ }^{3}$, Manassés \\ Vitorino de Oliveira ${ }^{1}$, Alessandro Tetsuo More ${ }^{1}$ \\ ${ }^{1}$ Instituto de Federal de Educação, Ciência e Tecnologia de São Paulo (IFSP) \\ Campus Votuporanga \\ Av. Jerônimo Figueira da Costa, 3014 - Pozzobon - Votuporanga, SP - Brasil \\ Grupo de Pesquisa CNPq: Tecnologias e práticas inovadoras aplicadas ao ensino \\ ${ }^{2}$ Faculdade de Tecnologia de São José do Rio Preto (Fatec) \\ Centro Estadual de Educação Tecnológica Paula Souza \\ Rua Fernandópolis, 2510 - Eldorado - S. J. Rio Preto, SP - Brasil \\ ${ }^{3}$ União das Faculdades dos Grandes Lagos - UNILAGO
}

prof.luciene@ifsp.edu.br,anaproj.eng@gmail.com,manavitorino@gmail.com,
alemore67@gmail.com

\begin{abstract}
Children are learning all the time, through numerous activities inside and outside the classroom, which allow the construction of knowledge through reading, writing, videos, games and exchange of experiences, making them more autonomous, self-taught, able to solve problems and work in teams. In this context, children should not consume only technology but building it in this way, this article reports the game programming teaching experience using Scratch with a group of 16 children 9-10 years of a municipal school in conjunction with the IFSP Votuporanga-SP campus, demonstrating an interdisciplinary way to improve logical reasoning in a collaborative and fun.
\end{abstract}

Resumo. Crianças estão aprendendo a todo momento, por meio de inúmeras atividades dentro e fora da sala de aula, que permitem a construção de conhecimento através de leitura, escrita, vídeos, jogos e troca de experiências, tornando-os mais autônomos, autodidatas, capazes de resolver problemas e trabalhar em equipe. Neste contexto, as crianças não devem apenas consumir tecnologia e sim construí-la, desta forma, este artigo relata a experiência de ensino de programação de jogos utilizando Scratch com um grupo de 16 crianças de 9 a 10 anos de uma escola municipal em conjunto com o IFSP campus Votuporanga-SP, demonstrando uma forma interdisciplinar de aprimorar o raciocínio lógico de forma colaborativa e divertida.

\section{Introdução}

As Tecnologias Digitais de Informação e Comunicação (TDIC), são cada vez mais utilizadas tendo em vista a ampliação do aprendizado e a possibilidade de mudanças diárias no âmbito educacional (Costa, Aguiar e Magalhães 2013, apud Aguiar, 2014). 
Para Mota et al (2014), é de conhecimento geral que a computação vai além do uso do computador para a realização de atividades rotineiras, podendo ser utilizado no desenvolvimento de novos programas ou jogos com diferentes funcionalidades, uma atividade que envolve conhecimentos de lógica de programação que podem ser aplicados em várias áreas, não se limitando a informática.

Entre os campos da educação, da comunicação social e da literatura, a tecnologia dos jogos eletrônicos para o primeiro representa uma promessa de aproximação dos sistemas de ensino em relação a tecnologia informacional contemporânea, para o segundo representa a emergência de uma nova mídia enquanto para o terceiro mostra-se uma enigmática forma textual a qual ainda bastante atrelada ao paradigma do impresso (Aranha, 2006, p.105-106).

De acordo com Valente (1993, p.10) a criança aprende mais quando ela é livre para explorar as relações por conta própria, ao invés de ser categoricamente ensinada. Está crescendo rapidamente, o percentual de professores de escolas públicas que utilizam a internet durante as aulas em 2013 foi 46\%, entre os recursos educacionais mais usados estão ilustrações, textos, vídeos, jogos, apresentações prontas e softwares educacionais (AGÊNCIA BRASIL, 2014).

De acordo com Rizzo (1988 apud Moratori, 2007, p.9), os jogos devem estar presentes todos os dias na sala de aula. Notadamente as pesquisas comprovam que a aprendizagem orientada ao desenvolvimento de competências por meio de tarefas ou projetos complexos, particularmente quando precisa da colaboração entre estudantes e está bem planejada, com uma adequada orquestração dos recursos, é uma ferramenta eficaz para que os alunos adquiram competências de pesquisa e, em um plano mais geral, outras competências relacionadas ao processamento da informação.

Dentro deste contexto, este artigo visa relatar a experiência com a execução do projeto de extensão com carga horária de 32 horas intitulado "Introdução a Programação para Crianças" que contou com 16 crianças de 9 a 10 anos, matriculadas na Escola Municipal Neyde Marão da cidade de Votuporanga. Serão relatados no decorrer do artigo aspectos pedagógicos, tecnológicos, a metodologia do curso e os resultados obtidos.

\section{Materiais e Métodos}

\subsection{Tecnologia e Práticas Pedagógicas no Contexto Escolar}

Para Oliveira (2013) a presença das TIC (Tecnologias da Informação e Comunicação) na escola deve ter como foco promover o acesso às informações, auxiliar na construção de conhecimentos, desenvolver novas habilidades como o uso de diferentes mídias, facilitar o processo de criação de redes colaborativas de aprendizagem e propiciar melhor interação entre a comunidade escolar (alunos, professores, pais e outros).

Segundo Idoeta (2014), muitos estudos ainda não encontraram correlações diretas entre uso da tecnologia e melhor aprendizado, mas observadores acreditam que se internet, tablets, computadores, aplicativos e outras plataformas forem usadas para estimular a imaginação dos alunos e amparar o trabalho do professor, com objetivos claros, podem ter impactos positivos não apenas nas notas, mas no desenvolvimento de habilidades e no engajamento dos estudantes. 
A interdisciplinaridade é característica da organização curricular e fator primordial para a inclusão de tecnologia em sala de aula, e para Poloni (2011, apud Silva (2012)), interdisciplinaridade significa "uma relação de reciprocidade, de mutualidade, que pressupõe uma atitude diferente a ser assumida rente ao problema do conhecimento, ou seja, é a substituição de uma concepção fragmentária para uma concepção unitária de ser humano, que pressupõe uma atitude de abertura, não preconceituosa, onde todo o conhecimento é igualmente importante, onde o conhecimento individual anula-se frente ao saber universal".

Segundo o "Documento-base: Tecnologias para a transformação da educação: experiências de sucesso e expectativas" elaborado no I Seminário Internacional de Tecnologias para a transformação da educação (2014), o que é verdadeiramente relevante nos dias de hoje é a aprendizagem do denominado "pensamento computacional" que, de acordo com a ISTE (International Society for Technology in Education) e a CSTA (Computer Science Teacher Association), é um processo que inclui, entre outros elementos: analisar problemas, organizar e representar dados de forma lógica, automatizar soluções mediante pensamento algorítmico, usar abstrações e modelos, comunicar processos e resultados, reconhecer padrões, generalizar e transferir. Softwares como Logo (Seymour Papert, 1980) já promoveram esse ensino por meio de uma linguagem desenvolvida especificamente para crianças.

Mota et al (2014) descrevem que quando o aluno usa o computador para construir o seu conhecimento, este passa a ser uma máquina para ser ensinada, propiciando condições para o aluno descrever a resolução de problemas, usando linguagens de programação, levando o aluno a refletir sobre os resultados obtidos e depurar suas ideias por intermédio da busca de novos conteúdos e novas estratégias. No Brasil as iniciativas de ensino de programação em sala de aula demoraram um pouco para tomar força, mas em algumas escolas, principalmente particulares, evidenciam-se grandes esforços no uso de Kits de robótica da LEGO, cadastro e incentivo de uso do CodeClub e até mesmo aulas e criação de jogos com HotPotatoes, Scratch e Greenfoot por crianças do ensino fundamental. Os alunos envolvidos em projetos como estes desenvolvem, assim, competências como o pensamento crítico, trabalho colaborativo e solução de problemas em diversas áreas do conhecimento: matemática, ciências experimentais, tecnologia e ciências da informação e da comunicação.

\subsection{Scratch}

Scratch é uma linguagem de programação visual gratuita, criada pelo Lifelong Kindergarten Group (LLK), grupo de pesquisa do MIT Media Lab (Massachusetts Institute of Technology). Trata-se de uma linguagem projetada especificamente para fins educacionais, tendo em vista jovens de oito a dezesseis anos. No entanto esta é usada por pessoas de todas as idades (MIT, s.d apud Aranha, 2013 e Silva, 2012).

Esta ferramenta é gratuita e pode ser utilizada online em sistemas operacionais Linux, Mac OS e Windows. Por não necessitar de nenhum conhecimento de outras linguagens de programação, esta é ideal para quem está começando a programar, por ser totalmente em interface gráfica, baseia-se nas ideias construcionistas do Logo (PAPERT, 1980) e do Etoys (KAY 2010; STEINMETZ, 2002 apud MALONEY et al., 2010) e permite a criação de artefatos como histórias interativas, jogos e animações 
(MALONEY et al., 2008). O Scratch possui uma interface semelhante à dos famosos blocos de Lego onde, é encaixado uma peça acima de outra até ser formado um padrão desejado por meio do conjunto de blocos (Figura 5), sendo que cada bloco possui um comando que podem ser agrupados de inúmeras formas e quando combinados formam programas sintaticamente corretos, tendo o usuário que focar apenas na lógica de funcionamento do seu projeto (MALAN et al., 2007). Para auxiliar os usuários a construírem seus artefatos de maneira envolvente, motivadora e pessoalmente significativa, Scratch facilita a importação e criação de vários tipos de mídia (imagens, sons, música), também existe uma comunidade on-line (http://scratch.mit.edu/) que permite aos usuários compartilharem seus projetos, receber feedback e encorajamento de seus pares e aprender colaborativamente com os projetos já publicados por outras pessoas (RESNICK et al., 2009). A meta principal do Scratch é introduzir a programação para quem não tem experiência no assunto.

Para Sobreira (2013) o uso do Scratch no contexto escolar propicia o desenvolvimento de habilidades e competências importantes para a formação do indivíduo, tais como as competências para a resolução de problemas e a concepção de projetos que se desenvolvem com o raciocínio lógico, a depuração de problemas, a produção de ideias, a atenção permanente e perseverante.

\begin{abstract}
“... quando se propicia aos alunos o desenvolvimento de atividades de forma desafiadora para ser executada através da produção de resultados advindos do uso de linguagem de programação, estamos solicitando muito mais que a elaboração de um produto, mas sim promovendo a oportunidade de execução de um ciclo contínuo, autoajustável e dinâmico de construção, reflexão e apropriação do conhecimento socialmente construído, que ocorrem de forma natural e dinâmica durante todo o processo de utilização e criação com o Scratch, colocando o aluno num papel singular no processo de aprendizagem e de construção do conhecimento, mediado por computador. Este papel promove essencialmente a autoria e o protagonismo infantil e possibilita a manutenção de competências e habilidades imprescindíveis para a formação do cidadão que atua no século XXI, de forma crítica, ativa, reflexiva e construtiva.” (Sobreira, 2013. Págs. 135)
\end{abstract}

Com a ferramenta Scratch é possível realizar inúmeras atividades pedagógicas que aliem pesquisa, programação e demonstração das atividades, o que contribui efetivamente para a promoção da contextualização curricular e da atribuição de significados aos conteúdos programáticos (Sobreira, 2013). Silva (2012) evidencia em seu trabalho com Scratch e a literatura de cordel, que o aluno deixa de ser um consumidor passivo e passa a ser construtor de seus próprios softwares, enquanto pano de fundo contribui para a criação de histórias contextualizadas ao cotidiano dos alunos.

Segundo o trabalho de Sobreira (2013) em suas atividades com estudantes de São Bernardo do Campo, destacam-se as principais atividades que podem ser realizadas com o Scratch como apoio ao conteúdo da matriz curricular, que são animações, jogos de tabuleiro, jogos digitais, jogos literários, quiz, entre outros. Gresse von Wangenheim, Nunes e Santos (2014) citam que ainda existem poucos estudos visando a integração do ensino de computação em disciplinas como a Língua Portuguesa ou Artes, um exemplo é o trabalho de Oliveira e Lopes (apud Gresse von Wangenheim, Nunes e Santos 
V Congresso Brasileiro de Informática na Educação (CBIE 2016)

Anais do XXII Workshop de Informática na Escola (WIE 2016)

(2014)) apresentando um estudo de impactos da experimentação lúdica e coparticipativa de crianças de 6 anos que programaram e animaram no Scratch histórias de poemas.

\subsection{Metodologia e Atividades Realizadas}

Segundo o trabalho de Gresse von Wangenheim, Nunes e Santos (2014) toda criança deve ter a oportunidade de aprender computação desde o Ensino Fundamental. Observase que o Ensino Fundamental foca somente no ensino da utilização de TI (IT literacy ou alfabetização digital), o que não é mais suficiente, sendo necessário ensinar a proficiência digital (IT fluency), acrescentando a capacidade de aprender e aplicar as novas tecnologias de forma produtiva ao longo da vida profissional/pessoal.

Visando criar um ambiente lúdico e com foco no ensino de proficiência digital, o curso de Extensão "Introdução à Programação para Crianças" foi realizado nos laboratórios do Instituto Federal de Educação, Ciência e Tecnologia de São Paulo (IFSP), campus Votuporanga, contando com carga horária total de 32 horas, separadas em encontros semanais com duração de 2 horas. Semanalmente as 16 crianças da Escola Municipal Neyde Marão, dois técnicos em informática que trabalham na escola e dois bolsistas do IFSP participaram, juntamente com a professora responsável pelo projeto das atividades do curso, cujo plano pode ser visto na Tabela 1.

Tabela 1. Conteúdo Programático do Curso

\begin{tabular}{|c|c|}
\hline Semana & Atividade \\
\hline 1 & $\begin{array}{l}\text { Apresentação do campus, da equipe de trabalho e das características do curso } \\
\text { Introdução ao pensamento computacional: desenho e programação do labirinto (Atividade Lúdica em } \\
\text { sala de aula convencional) }\end{array}$ \\
\hline 2 & $\begin{array}{l}\text { Apresentação do Scratch com uso da lousa digital em laboratório de informática } \\
\text { Atividade 1: Animação de dança (conceitos de movimento, posicionamento, palco, atores e blocos de } \\
\text { comandos básicos) }\end{array}$ \\
\hline 3 & $\begin{array}{l}\text { Atividade 2: Desenho e programação do labirinto, animação e emissão de sons, estrutura de repetição } \\
\text { (sempre) }\end{array}$ \\
\hline 4 & Atividade 3: Carro - Movimentação através das setas, estruturas de controle (se) \\
\hline 5 & $\begin{array}{l}\text { Atividade 4: Colhendo frutas - Criação de variável e operações para pontuação, esconder e exibir } \\
\text { atores em tempo de execução }\end{array}$ \\
\hline 6 & $\begin{array}{l}\text { Atividade 5: Caça-fantasmas - Movimentação de atores através do mouse, uso de programação do } \\
\text { clique, variáveis para controle de pontos (ganhar e perder pontos) }\end{array}$ \\
\hline 7 & Atividade Avaliativa: Questões impressas de múltipla escolha e um desafio (Chute a gol) \\
\hline 8 & $\begin{array}{l}\text { Atividade 6: Campo de futebol - Aprimorando o chute a gol, controle de ações e movimentação da } \\
\text { bola, ângulos e pontuação }\end{array}$ \\
\hline 9 & \multirow{2}{*}{ Atividade 7: Uso do jogo Race Cars (Scratch) e criação do seu próprio Rally } \\
\hline 10 & \\
\hline 11 & \multirow{2}{*}{$\begin{array}{l}\text { Atividade 8: Pescaria - o mergulhador lança a rede em direção aos animais marinhos, criação de } \\
\text { fantasias e movimentos aleatórios dos peixes }\end{array}$} \\
\hline 12 & \\
\hline 13 & $\begin{array}{l}\text { Atividade 9: Números Ninja - Controle de eventos com números caindo aleatoriamente e implantação } \\
\text { de regras do jogo }\end{array}$ \\
\hline 14 & \multirow{2}{*}{$\begin{array}{l}\text { Atividade Final: Reciclagem - os alunos foram desafiados a descrever a importância da reciclagem, } \\
\text { desenhar as lixeiras representando os tipos de lixo separados e descrever } 6 \text { objetos que poderiam ser } \\
\text { colocados em cada lixeira (no papel). Na segunda etapa deve-se criar o palco e desenhar as lixeiras, } \\
\text { buscar as } 36 \text { imagens na internet, gravá-las no computador e importá-las como atores no jogo. A etapa } \\
\text { final é realizar a programação para quando o usuário arrastar o lixo para a lixeira correta adicionar } \\
\text { pontos e exibir uma mensagem. Se arrastar o lixo para a lixeira errada o usuário perde pontos e emite } \\
\text { uma mensagem }\end{array}$} \\
\hline 15 & \\
\hline 16 & Encerramento e entrega dos certificados \\
\hline
\end{tabular}


Além do ensino de programação e desenvolvimento do raciocínio lógico das crianças, a presença dos técnicos, concursados na rede municipal de ensino e responsáveis pelos laboratórios de informática da escola foi proposital, visto que eles também recebiam treinamento em relação à metodologia utilizada, acompanhavam as aulas e as exposições, recebiam o material das aulas com antecedência e eram incentivados a continuar com novas atividades em suas escolas, visto que a maioria dos alunos estavam matriculados em tempo integral. As atividades dos bolsistas consistiam em auxílio à elaboração de alguns jogos, impressão do material, testes das atividades e desafios propostos em cada aula.

Os alunos também desenvolviam outras atividades usando o Scratch quando não estavam no IFSP, como a criação de animações relacionadas com os livros de estórias que a professora estava trabalhando em sala de aula, o que os motivava a ler o livro e adaptá-lo ao meio digital em suas animações, também incentivava o pensamento criativo, pois os alunos tinham que desenhar os personagens para poder animá-los.

\section{Resultados}

O curso foi realizado com o uso de salas de aula (Figura 2) e laboratórios de Informática (Figura 4 a e b), contando com várias atividades fora do computador, como a montagem dos comandos necessários (recortados em EVA e disponíveis todos misturados) para que o personagem passe por todo o labirinto e chegue ao destino. A recompensa para a conclusão deste desafio era um saquinho com guloseimas para os alunos. Também foram realizadas atividades práticas no computador, tais como pesquisas na internet e criação dos jogos utilizando o Scratch, que visam aliar diversas atividades e desafios para os alunos, lembrando sempre que o computador é um "meio" e não um "fim" em si, ele ajuda a criar os jogos e não pensa sozinho, o aluno deve raciocinar sobre o jogo, elencar as regras e depois definir os comandos necessários para que os personagens executem o desejado.

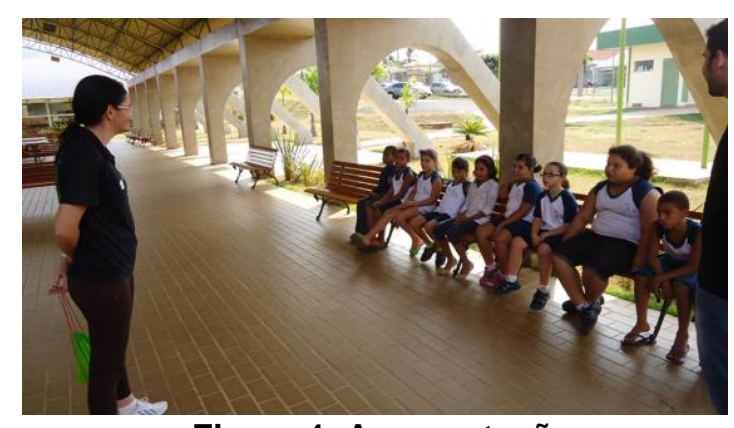

Figura 1. Apresentação

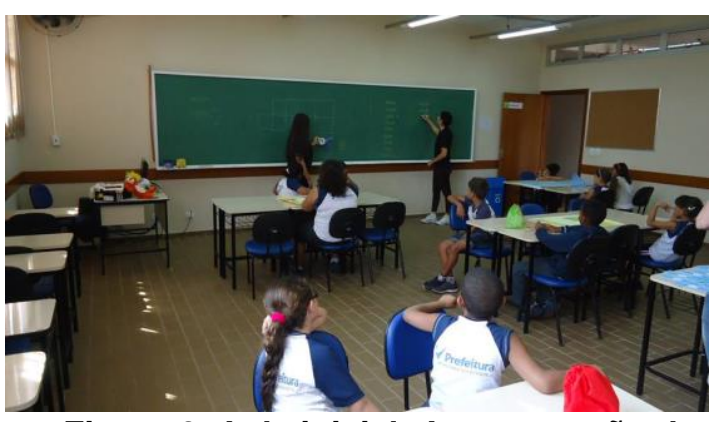

Figura 2. Aula inicial: Apresentação do Pensamento Computacional

Como atividades da aula inicial os alunos receberam uma cartolina com um labirinto desenhado, uma cartolinha em branco, um personagem (que foi escolhido pelos alunos após um teste com 25 expressões matemáticas) e em outra mesa estavam misturados vários comandos MOVA e GIRE (similares aos do Scratch). Os alunos deveriam colocar o personagem no início do labirinto e separar o conjunto de comandos necessários para que o personagem chegasse ao final para receber o prêmio (Figura 3). 
V Congresso Brasileiro de Informática na Educação (CBIE 2016)

Anais do XXII Workshop de Informática na Escola (WIE 2016)
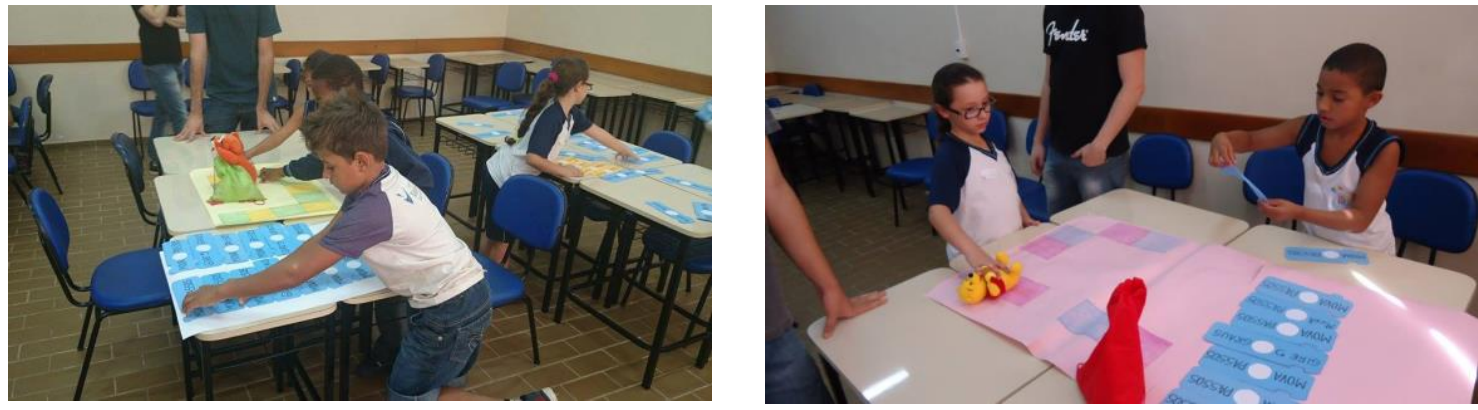

Figura 3. Separação e "Programação" dos passos

$\mathrm{Na}$ primeira aula no laboratório de informática foi demostrado como tudo funcionava, não foi preciso ensinar como ligar ou desligar o computador, ou como acessar a internet, foi mostrado o acesso ao site do Scratch e realizada a primeira animação de um personagem dançando. O impacto da ferramenta foi muito motivador, os alunos gostaram muito de arrastar e soltar alguns blocos e o personagem começar a dançar na tela. Posteriormente foram editados o palco, sons e foi gravada cada animação com uso de usuário e senha. $\mathrm{Na}$ aula seguinte os alunos novamente foram agrupados para executar o desenho e criação dos comandos para que o personagem percorra o labirinto (Figura 4 a e b).

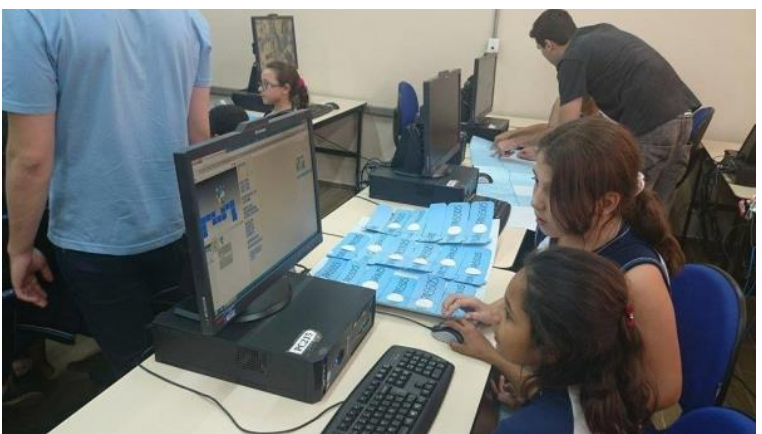

Figura 4. a) Programação do labirinto

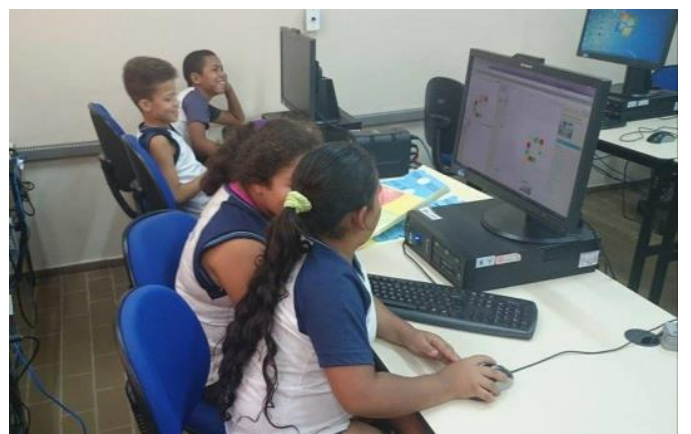

b) Discussões em grupo

Para os demais jogos os alunos recebiam um tutorial impresso (sempre com no máximo 4 páginas) com a aula (jogo) a ser desenvolvido contendo um ou mais desafios. A cada aula (Tabela 1) os jogos foram ficando mais complexos, a fim de exemplificar o uso completo da ferramenta e desenvolver o raciocínio lógico e a capacidade de resolução de problemas (Figuras 7, 8 e 9).

A avaliação possuía 13 questões, sendo 12 de múltipla escolha e 1 jogo e foi realizada em grupos de três alunos. As questões de múltipla escolha solicitavam trechos ou blocos de código que estavam faltando em algum jogo ou um comando específico (Figura 6). Todos os grupos obtiveram mais de $80 \%$ de acerto.

1 - O Ator do cenário abaixo quer dançar, então ajude-o mostrando qual é o comando que está faltando:

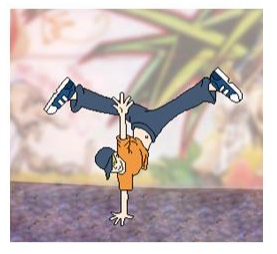

Mova

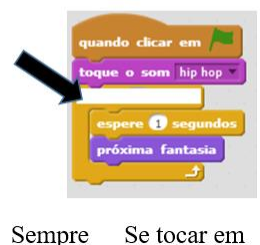

Figura 6. Exemplos de questões da avaliação
4 - Qual dos blocos de comando abaixo fará o personagem aparecer na tela do seu jogo:

gire mova esconder mostrar

5 - Qual dos blocos de comando abaixo fará com que o personagem mude de fantasia:

Mova Mostrar Mude para a fantasia 
V Congresso Brasileiro de Informática na Educação (CBIE 2016)

Anais do XXII Workshop de Informática na Escola (WIE 2016)
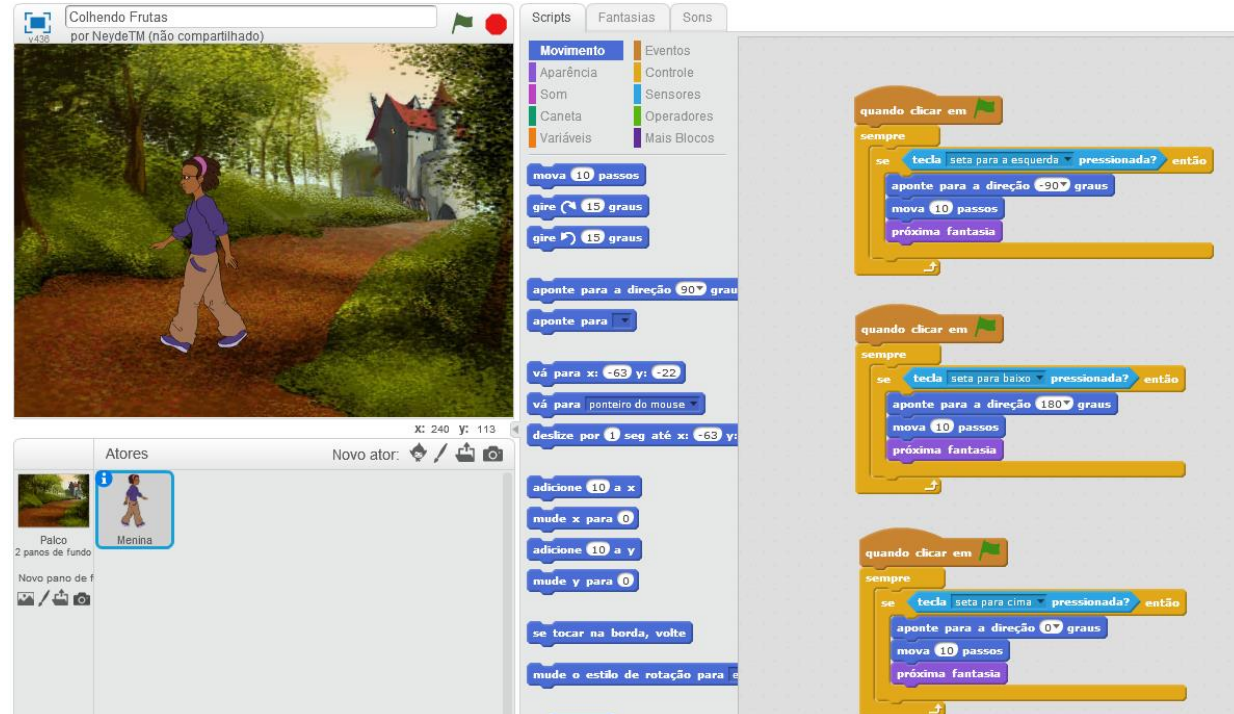

Figura 7. Colhendo Frutas
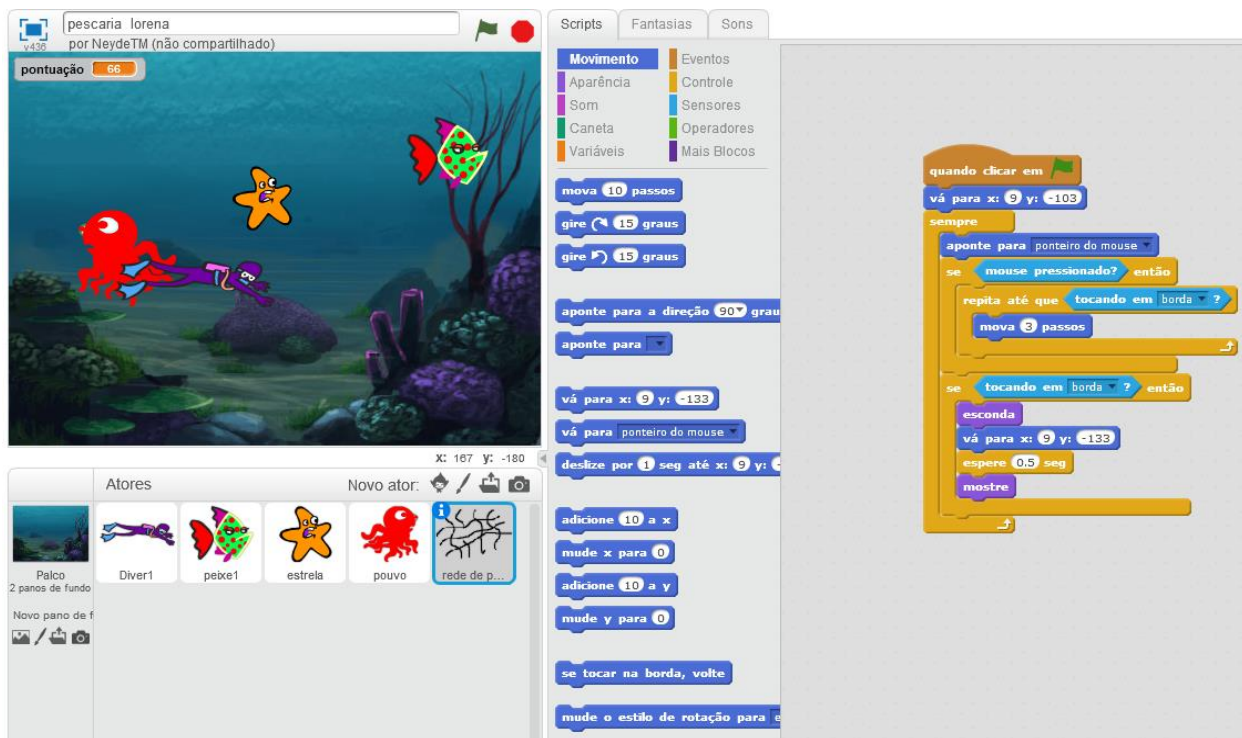

Figura 8. Pescaria
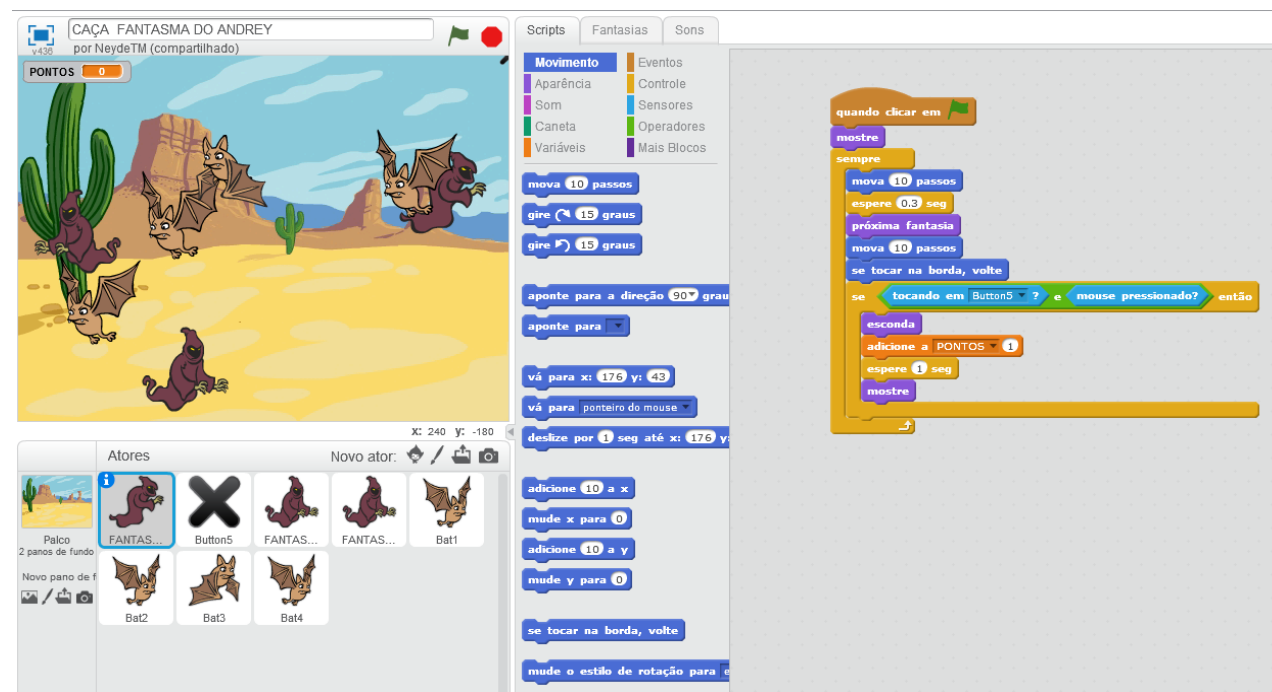

Figura 9. Caça fantasmas 
V Congresso Brasileiro de Informática na Educação (CBIE 2016)

Anais do XXII Workshop de Informática na Escola (WIE 2016)

\section{Conclusões}

Scratch possibilita a aprendizagem baseada no conceito de design, abordagem que, segundo Brennan (2011 apud Sobreira 2013), enfatiza a concepção (criar e não apenas utilizar ou interagir), a personalização (criando algo que é pessoalmente significativo e relevante), a colaboração (trabalhando com outras pessoas nas criações) e a reflexão (revendo e repensando as práticas criativas de cada um).

De acordo com a Partnership for the 21st Century (2003), o ambiente apoia o desenvolvimento de habilidades de aprendizagem do século XXI, onde os autores destacam as formas como Scratch suporta o desenvolvimento de tais habilidades: Habilidades de informação e comunicação, por meio da seleção, criação e gerenciamento múltiplas formas de mídia, incluindo texto, imagens, animações e gravações de áudio, tornando-se mais perspicazes e críticos ao analisar os meios de comunicação que veem ao redor deles. Desenvolvem habilidades de pensar e resolver problemas pois à medida que aprendem a programar, os estudantes aprimoram seu raciocínio crítico e pensamento sistemático no desenvolvimento de suas soluções, encorajando o pensamento criativo ao envolver os aprendizes na busca de soluções inovadoras para problemas, não apenas aprender a resolver um problema predefinido, mas estar preparado para chegar a novas soluções para os desafios que surgirem. Habilidades interpessoais, quando os estudantes trabalham em projetos que sejam pessoalmente significativos, as suas ideias fornecem motivação interna para a superação de desafios e frustrações encontradas no processo de concepção e resolução de problemas.

O uso de ferramentas interativas e gratuitas em atividades escolares faz com que os alunos apliquem seus conhecimentos para o desenvolvimento de jogos que vão desde as necessidades básicas de alfabetização até a fixação de conteúdos de química, física, história, geografia ou artes. Os projetos devem envolver a escola toda, tornando-a uma comunidade conectada e disposta a mudar seu papel na sociedade de meros consumidores de tecnologia para grandes produtores de tecnologia. Isso desenvolve nos alunos o espírito de liderança, responsabilidade e confiança, fatores que serão decisivos no mercado de trabalho e propiciarão novos horizontes.

O uso da tecnologia em sala de aula ainda gera grandes debates entre educadores e acadêmicos, pois atualmente é impensável ignorar a importância da tecnologia na vida das pessoas. Porém, seu uso efetivo para fins cognitivos e de aprendizagem precisa ter direcionamento correto para não se transformar apenas em diversão.

Nota-se que na experiência relatada neste trabalho, é possível aliar conteúdos teóricos ao desenvolvimento de aplicações práticas, como por exemplo, o jogo de reciclagem e a animação de um livro, tornando o processo de ensino-aprendizagem mais lúdico e centrado no estudante, utilizando várias habilidades, criatividade e interesse dos alunos e professores.

\section{Referências}

AGUiAR, J. J. B.; FECHINE, J. M.; COSTA, E. B. (2014). Estilos Cognitivos e Estilos de Aprendizagem em Informática na Educação: um mapeamento 
sistemático focado no SBIE, WIE e RBIE. Disponível em: <http://www.brie.org/pub/index.php/sbie/article/view/2972/2705>

ARANHA, G. (2006). Jogos Eletrônicos como um conceito chave para o desenvolvimento de aplicações imersivas e interativas para o aprendizado. Ciênc. cogn. [online]. 2006, vol.7, n.1, pp. 105-110. ISSN 1806-5821. Acesso em: 12 jul. 2014.

GRESSE VON WANGENHEIM, C.; NUNES, V. R.; SANTOS, G. D. (2014). Ensino de Computação com SCRATCH no Ensino Fundamental - Um Estudo de Caso. Revista Brasileira de Informática na Educação, [S.1.], v. 22, n. 03, p. 115, nov. 2014. ISSN 1414-5685. Disponível em: <http://www.brie.org/pub/index.php/rbie/article/view/2885>. Acesso em: 12 Mai. 2015. doi:http://dx.doi.org/10.5753/rbie.2014.22.03.115.

IDOETA, P. A. Dez tendências da tecnologia na educação. BBC Brasil em São Paulo, 6 de dezembro de 2014. Disponível em: <http://www.bbc.co.uk/portuguese/noticias/2014/12/141202_tecnologia_educacao_pai $>$ _Acesso em: 09-12-2014

MORATORI, P. B. (2003). Por que utilizar jogos educativos no processo de ensino aprendizagem. UFRJ. Rio de Janeiro.

MOTA, F. P. et al. Desenvolvendo o Raciocínio Lógico no Ensino Médio: uma proposta utilizando a ferramenta Scratch. In: Anais do $25^{\circ}$. Simpósio Brasileiro de Informática na Educação. $3^{\circ}$. Congresso Brasileiro de Informática na Educação. Nov. 2014. Dourados, MS. Disponível em: < http://www.brie.org/pub/index.php/sbie/article/view/2964/2698>

OLIVEIRA, E. D. Tecnologia e Educação. In: XI Encontro de Pesquisadores do Programa de Pós-Graduação em Educação. 29 e 30 Nov. 2013. São Paulo, SP. Disponível em: <http://www.ced.pucsp.br /encontro_pesquisadores_2013/downloads/anais_encontro_2013/oral/elda_damasio_ de_oliveira.pdf >. Acesso em: 09-12-2014.

SILVA, A. R. O. S., TAVARES, M. A. O. (2012). Intervenção Interdisciplinar Através do Scratch Literatura de Cordel e a Programação de Computadores. Revista Científica Práticas Pedagógicas: Registros e Reflexões. Vol. 1 no. 2. 2012. Págs. 1 - 17. Disponível em: 〈http://praticaspedagogicas.colegionovotempo.com.br〉

SOBREIRA, E. S. R.; TAKINAMI, O. K.; SANTOS, V. G. (2013) Programando, Criando e Inovando com o Scratch: em busca da formação do cidadão do século XXI.. II Congresso Brasileiro de Informática na Educação (CBIE 2013) II Jornada de Atualização em Informática na Educação (JAIE 2013). [s.1.] Capítulo 6. págs. 126 152. Disponível em: <http://www.brie.org/pub/index.php/pie/article/view/2592/2248>. Acesso em: 12 Mai. 2015. doi: 10.5753/CBIE.JAIE.2013.126. 